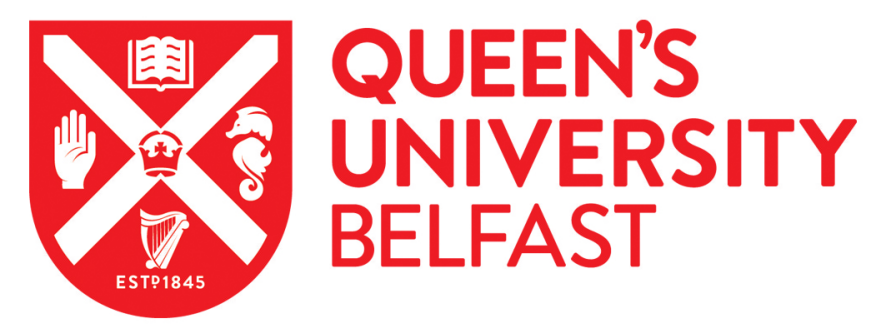

\title{
An assessment of vascularity and flow intensity of the placenta in normal pregnancy and pre-eclampsia using three-dimensional
} ultrasound

Costa, J., Rice, H., Cardwell, C., Hunter, A., \& Ong, S. (2010). An assessment of vascularity and flow intensity of the placenta in normal pregnancy and pre-eclampsia using three-dimensional ultrasound. The Journal of Maternal-Fetal \& Neonatal Medicine, 23(8), 894-899. https://doi.org/10.3109/14767051003649862

Published in:

The Journal of Maternal-Fetal \& Neonatal Medicine

Queen's University Belfast - Research Portal:

Link to publication record in Queen's University Belfast Research Portal

\section{General rights}

Copyright for the publications made accessible via the Queen's University Belfast Research Portal is retained by the author(s) and / or other copyright owners and it is a condition of accessing these publications that users recognise and abide by the legal requirements associated with these rights.

\section{Take down policy}

The Research Portal is Queen's institutional repository that provides access to Queen's research output. Every effort has been made to ensure that content in the Research Portal does not infringe any person's rights, or applicable UK laws. If you discover content in the Research Portal that you believe breaches copyright or violates any law, please contact openaccess@qub.ac.uk. 


\title{
An assessment of vascularity and flow intensity of the placenta in normal pregnancy and pre-eclampsia using three-dimensional ultrasound
}

\section{JANITHA COSTA ${ }^{1,2}$, HELEN RICE $^{1}$, CHRIS CARDWELI ${ }^{3}$, ALYSON HUNTER ${ }^{1}$, \& STEPHEN ONG ${ }^{1}$}

\author{
${ }^{1}$ Department of Obstetrics and Gynaecology, Royal fubilee Maternity Hospital, Belfast, UK, ${ }^{2}$ Department of Obstetrics and \\ Gynaecology, Antrim Area Hospital, Antrim, UK, and ${ }^{3}$ Department of Epidemiology and Statistics, Queens University \\ Belfast, Belfast, UK
}

(Received 2 December 2009; revised 19 February 2010; accepted 18 December 2009)

\begin{abstract}
Objective. To test the hypothesis that parameters of vascularity and flow intensity of the placenta as determined by threedimensional (3D) ultrasound, (1) are different in normal pregnancy compared to pre-eclampsia (2) decrease from the basal plate towards the chorionic plate.

Methods. Twenty women with normal pregnancy and 17 women with pre-eclampisa were studied. 3D power Dopplex ultrasound was used to acquire individual placental volumes. Rotational measurements of placental volumes were acquired using virtual organ computer aided analysis (VOCAI ${ }^{T M}$ ). The power Doppler signals were then semi-quantified within 'histogram facility', which generates three vascularity and fiow intensity parameters: flow index (FI), vascular index (VI) and vascularisation flow index (VFI).

Results. FI, VI and VFI were lower in pre-eclampsia compared to normal pregnancy in all regions of the placenta. This difference was statistically significant in most regions of the placenta after accounting for gestational age, body mass index and placental site. We were not able to demonstrate a decreasing gradient of these parameters from basal plate to chorionic plate.

Conclusion. 3D ultrasound to assess placental vascularity and flow intensity appears to be an interesting research tool. However, other indices derived from Power Doppler may be more relevant to obstetric practice.
\end{abstract}

Keywords: Flow intensity, insonnation, power Doppler angiography, pre-eclampsia, three-dimensional ultrasound, vascularity

\section{Introduction}

In pre-eclampsia, there is reduced placenta perfusion due to inadequate trophoblastic invasion of the spiral arteries within the placental bed $[1,2]$. The assessment of placental perfusion is fraught with difficulty. Both uterine and umbilical artery Doppler ultrasound assessments are indirect evaluations of the placental bed and do not assess placental perfusion.

Recently, the direct investigation of the in vivo placenta has apparently become possible using three-dimensional (3D) power Doppler ultrasonography [3-7]. Three main indices are described in the literature: flow index (FI), vascular index (N) and vascularisation flow index (VFD). All three indices. are validated by flow phartom studies $[8-10]$ and they are reproducible $[4,11,12]$. How ever, none of these indices can be used to calculate perfusion in its conventional sense. Currently, these indices are believed to reflect vascularity and fow intensity $[12,13]$. Despite the fact that these indices do not equate with perfision per se, they lave attracted much attention as they have been presamed 
to provide an assessment of vascularity (or a surrogate of perfusion) of the placenta $[3-5,7]$.

Guiot et al. [3] demonstrated that these 3D parameters of vascularity and flow intensity were reduced in pregnancies complicated by intrauterine growth restriction (IUGR). We hypothesise that a reduction in these parameters can also be demonstrated in pre-eclampsia.

Given that the region where the spiral arteries exist is at the basal plate, it would seem plausible that these vascularity and flow intensity parameters would decrease progressively from the basal plate towards the chorionic plate (as blood flows from the myometrium towards the chorionic plate). This supposition was supported by recent work using magnetic resonance imaging [14]. We hypothesise that it is also possible to demonstrate a reduction in vascularity and flow intensity parameters from the basal to chorionic plate using $3 \mathrm{D}$ ultrasound.

\section{Materials and methods}

We studied 20 patients with a normal pregnancy and 17 patients with pre-eclampsia between the gestations of 20 and 41 weeks. Normal pregnancy was defined as a pregnancy where the mother has no medical conditions and is on no medications and the foetus is appropriately grown. We defined pre-eclampsia where there was hypertension and significant proteinuria after 20 weeks of gestation. Hypertension was defined as blood pressure $>140$ / $90 \mathrm{mmHg}$ on two successive occasions $4 \mathrm{~h}$ apart. Significant proteinuria was defined as $>+2$ on urinalysis or $>0.3 \mathrm{~g} / \mathrm{l}$ or $>0.5 \mathrm{~g} / 24 \mathrm{~h}$. Pregnancies where the foerus was chromosomally abnormal and multiple pregnancies were excluded from the study. The study was approved by our local ethics committee and research governance deparment. Informed consent was obtained from all the women.
All women had a single $3 \mathrm{D}$ ultrasound scan to assess the placenta. Imaging was conducted by a single observer using a Voluson $E 8^{\mathrm{TM}}$ machine (GE Kretz) and a $6 \mathrm{MHz}$ transabdominal probe. 3D power Doppler angiography (3D-PDA) was used to acquire placental volumes in three different sampling sites: the basal plate, the chorionic plate and the region in between these two plates (Figure 1). The region of insonnation was midway between the cord insertion and the placental edge. The 3D volume box was placed at a fixed $85^{\circ}$ angle. Volume acquisition was made at a time interval of $10 \mathrm{~s}$. Thirty-degree rotational measurements of placental volume were acquired using virtual organ computer aided analysis (VOCAL ${ }^{T M}$ ) as described elsewhere $[3-5,8,12]$. To standardise the procedure, we selected a constant spherical sample volume (Figures 1 and 2). The power Doppler signals were then semiquantified within the 'histogram facility', which generates the three indices of vascularity, namely FI, VI and VFI. The settings of the equipment such as gain signal power, puise repetition frequency (PRF) and speed of acquisition also influence the indices $[8-10,15]$; hence these were controlled for. Maximal sensitivity was ensured by setring the PRF to $0.6 \mathrm{kHz}$ and wall motion filter to 'low 1 '. The following default settings were used: frequency, mid; dynamic, set 3 ; balance, $>150$; smooth, 4/5; ensemble, 11; line density, 8; power Doppler map, 4; artifact suppression, off; power Doppler line filter, off; quality, high.

\section{Statistical analysis for differences between normal pregnancy and pre-eclampsia}

The mean and standard deviation of mean were calculated for FI (as FI was approximately normally distributed) and the median and inter quartile range were calculated for VI and VFI (as VI and VFI were skewed) for pre-eclampsia and normal pregnancies

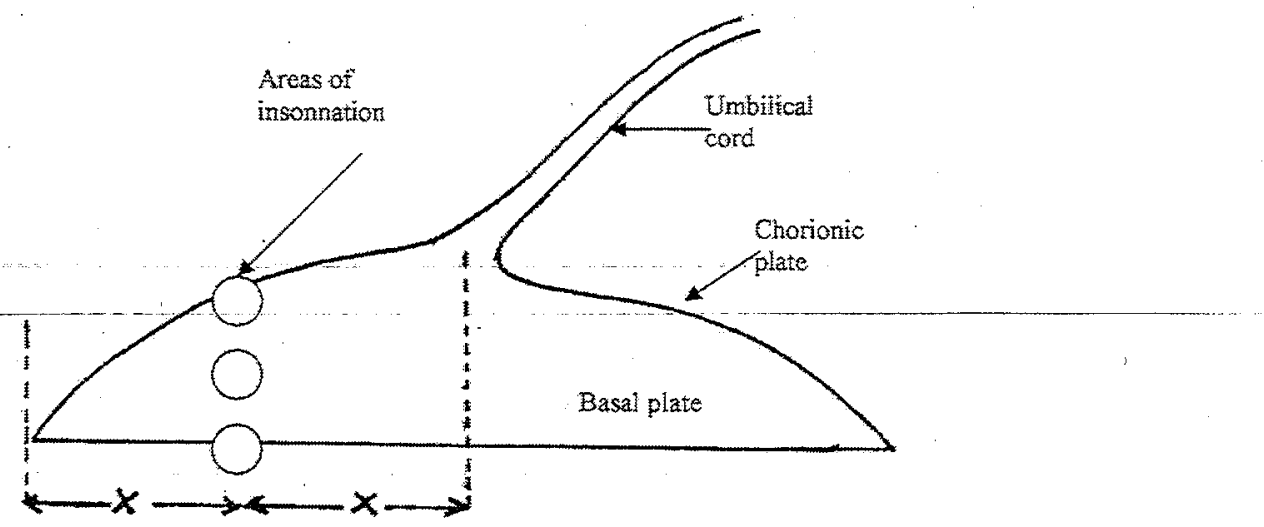

Figure 1. Regions of insomnation at chorionic plate, the basal plate and the region in between (the 'mid region'). The regions chosen are equidistant from the cord insertion and the edge of the placenta. 
(Tables I-III). The mean of FI was compared between the normal and pre-eclampsia groups using an independent samples $t$ test. Data for VI and VFI were $\log$ transformed and differences between groups were compared using a $t$ test. The resulting differences in means for VI and VFI were transformed to give the ratio of geometric means [16]. As the indices FI, VI and VFI are known to change with gestation, body mass index (BMI) and the placental site $[5,6,8]$, we calculated adjusted differences in means for $\mathrm{FI}$ (and adjusted ratios of geometric means for VI and VFI using linear regression including gestational age, $\mathrm{BMI}$ and placental site in the model. (Tables I-III)

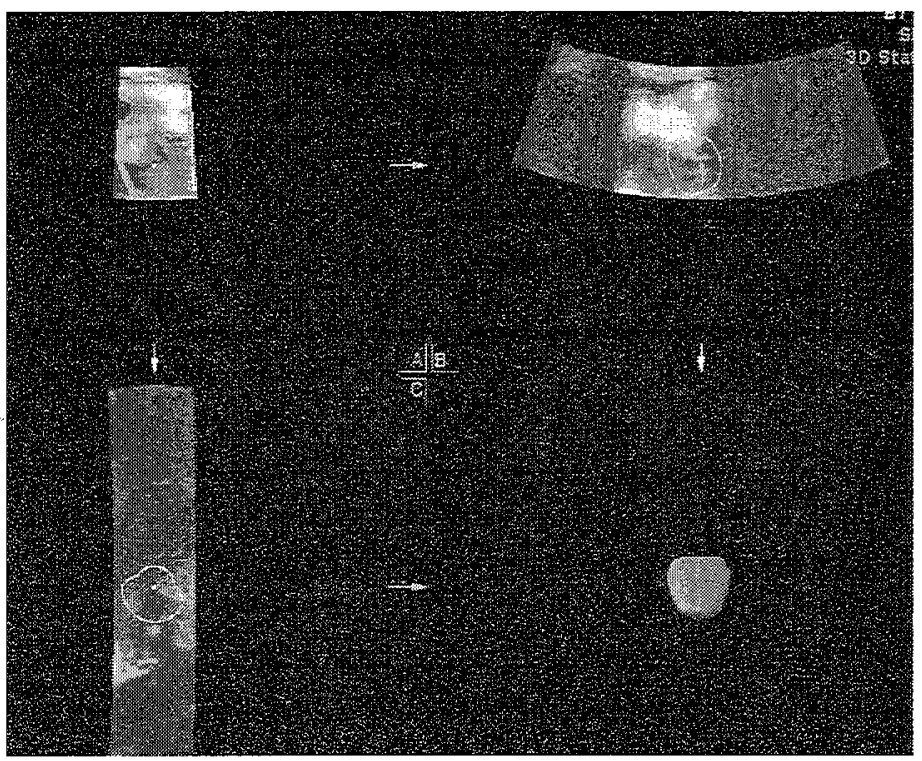

Figure 2. Images showing three orthogonal planes and the rendered view within the region of interest. The size of the region of interest is kept constant.

Table I. Difference in FI between pre-eciampsia and nomal pregnancy.

\begin{tabular}{|c|c|c|c|c|c|c|}
\hline & \multirow{2}{*}{$\frac{\begin{array}{c}\text { Pre-eclampsia } \\
(n=17)\end{array}}{\text { Mean (SD) }}$} & \multirow{2}{*}{$\begin{array}{c}\begin{array}{c}\text { Normal } \\
(n=20)\end{array} \\
\text { Mean (SD) }\end{array}$} & \multicolumn{2}{|c|}{ Unadjusted } & \multicolumn{2}{|c|}{$\begin{array}{l}\text { Adjusted (for gestational } \\
\text { age, BMI and placental site) }\end{array}$} \\
\hline & & & $\begin{array}{l}\text { Difference in } \\
\text { mean }(95 \% \mathrm{Cn})\end{array}$ & $p$-value & $\begin{array}{l}\text { Difference in } \\
\text { mean }(95 \% \mathrm{Cl})\end{array}$ & $p$-value \\
\hline Basal plate & $39.96(12.76)$ & $4.5 .43(17.99)$ & $5.47(16.00,5.11)$ & 0.30 & $6.79(17.39,3.81)$ & 0.20 \\
\hline Mid region & $23.86(8.69)$ & $31.75(7.58)$ & $7.90(13.33,2.47)$ & $<0.01$ & $8.68(13.39,3.97)$ & $<0.01$ \\
\hline Chorionic plate & $35.99(11.26)$ & $39.24(18.19)$ & $3.25(13.57,7.07)$ & 0.53 & $3.91(13.95,6.13)$ & 0.43 \\
\hline
\end{tabular}

$\mathrm{SD}$, standard deviation; $\mathrm{Cl}$; confidence interval; BMI, Body Mass Index; $p$, significance of difference between pre-eciampsia and norma pregnancy.

Table II. Difference in VI between pre-eclampsia and normal pregnancy.

\begin{tabular}{|c|c|c|c|c|c|c|}
\hline & $\begin{array}{c}\text { Pre_eclampsia } \\
\quad(n=17)\end{array}$ & $\begin{array}{l}\text { Normal } \\
(n=20)\end{array}$ & Unadjusted & & $\begin{array}{l}\text { Adjusted (for ges } \\
\text { age, BMI and place }\end{array}$ & $\begin{array}{l}\text { onal } \\
\text { al site) }\end{array}$ \\
\hline & Median (IQR) & Median (IQR) & $\begin{array}{l}\text { Ravio of geomerric } \\
\text { mean }(95 \% \mathrm{CI})\end{array}$ & $p$-value & $\begin{array}{l}\text { Ratio of geometric } \\
\text { mean }(95 \% \mathrm{CD})\end{array}$ & $p$-value \\
\hline Basal plate & $6.00(18.91)$ & $23.41(20.64)$ & $0.27(0.09 ; 0.82)$ & 0.02 & $0.25(0.08,0.80)$ & 0.02 \\
\hline Mid region & $0.51(1.00)$ & $8.90(13.00)$ & $0.07(0.02,0.22)$ & $<0.01$ & $0.09(0.03,0.30)$ & $<0.01$ \\
\hline Chorionic plate & $\therefore \quad 3.40(13.40)$ & $18.10(21.37)$ & $0.23(0.05,1.11)$ & 0.07 & $0.26(0.07,0.95)$ & 0.04 \\
\hline
\end{tabular}

SD, standard deviation; CI, confidence interval; BMI, Body Mass Index; $p$, significance of difference between pre-eclampsia and normal pregnancy. 
Table II. Difference in VFI between pre-eclampsia and normal pregnancy.

\begin{tabular}{|c|c|c|c|c|c|c|}
\hline \multirow{2}{*}{$\cdots$} & \multirow{2}{*}{$\begin{array}{c}\text { Pre-eclampsia } \\
\frac{(n=17)}{\text { Median }} \\
(\text { IQR })\end{array}$} & \multirow{2}{*}{$\begin{array}{c}\begin{array}{c}\text { Normal } \\
(n=20)\end{array} \\
\begin{array}{c}\text { Median } \\
(\mathrm{IQR})\end{array}\end{array}$} & \multicolumn{2}{|c|}{ Unadjusted } & \multicolumn{2}{|c|}{$\begin{array}{l}\text { Adjusted (for gestational } \\
\text { age, BMI and placental site) }\end{array}$} \\
\hline & & & $\begin{array}{l}\text { Ratio of geomerric } \\
\text { mean }(95 \% \mathrm{CI})\end{array}$ & $p$-value & $\begin{array}{l}\text { Ratio of geometric } \\
\text { mean }(95 \% \mathrm{CI})\end{array}$ & $p$-value \\
\hline Basal plate & $16.60(22.45)$ & $49.00(71.76)$ & $0.10(0.03,0.30)$ & 0.04 & $0.23(0.08,0.67)$ & $<0.01$ \\
\hline Mid region & $2.49(3.00)$ & $25.80(31.00)$ & $0.29(0.86,0.06)$ & $<0.01$ & $0.06(0.02,0.20)$ & $<0.01$ \\
\hline Chorionic plate & $10.76(23.84)$ & $34.20(33.00)$ & $2.23(0.05,1.11)$ & 0.07 & $0.15(0.04,0.58)$ & $<0.01$ \\
\hline
\end{tabular}

SD, standard deviation; $\mathrm{CI}$, confidence interval; BMI, Body Mass Index; $p$, significance of difference between pre-eclampsia and normal prëgiancy.

Statistical analysis for differences from the basal to the chorionic plate

FI, VI and VFI were compared in the basal, mid and chorionic regions (Figure 1) using Friedman's tests. This test was followed by Wilcoxon-signed rank test (with Bonferroni correction to adjust for the multiple comparisons) to identify the regions between which the differences were statistically significant.

\section{Results}

The mean gestational age was 35 weeks (range $31-$ 41 ) and 33 weeks (range 32-40) for normal pregnancy and pre-eclampsia, respectively. For women with pre-eclampsia, the average mean arterial pressure was $115 \mathrm{mmHg}$ (range 109-120 $\mathrm{mmHg}$ ). The mean BMI was 26 (range 22-34) for normal pregnancy and 26 (range 19-38) for pre-eclampsia.

Of all three parameters only FI showed a normal distribution with little variability both in pre-eclampsia and normal pregnancy while VI and VFI had a skewed distribution with high variability in both groups.

\section{Differences between pre-eclampsia and normal pregnancy}

All parameters (FI, VI and VFI) were lower in preeclampsia compared to normal pregnancy in all three regions of placenta (Figures 3-5).

The means for FI in pre-eclampsia and normal pregnancy were 39.96 and 45.43 in basal plate, 23.86 and 31.75 in mid region and 35.99 and 39.24 in chorionic plate with the difference being significant in mid region. $(p<0.01)$. This difference was also statistically significant after adjustment for gestation, BMI and placental site $(p<0.01)$ (Table I).

Similarly for $V I$ and $V H I$, there were significant differences in some regions of the placenta between preeclampsia and normal pregnancy (Tables II and III).

Differences from the basal to the chorionic plate

\section{Basal Plate}

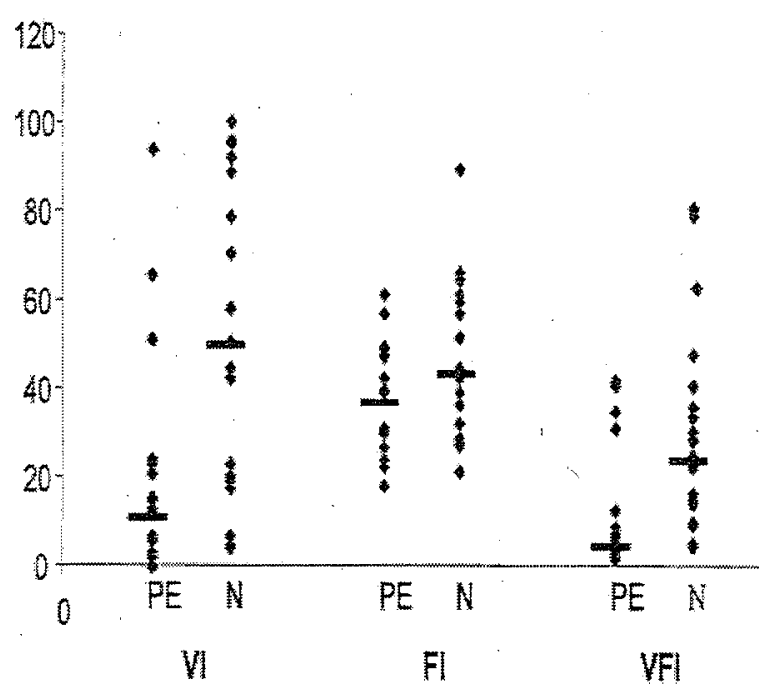

Figure 3. Plot for VI, FI and VFI in pre-clampsia (PE) and normal pregnancy (N) at the basal plate. The horizontal bar indicates the median for VI and VFI and mean for $\mathrm{FL}$.

and chorionic regions (medians of 40,27 and 36 respectively; Friedman $p<0.01$ ). Paired test indicated that these differences were statistically significant between the mid and basal region (Wilcoxon-signed rank test $p<0.01$ ), the mid and chorionic region (Wilcoxon-signed rank test $p<0.01$ ) but not between the chorionic and basal plate (Wilcoxon-signed rank test $p=0.84$ ).

Similar differences were found in the basal, mid and chorionic regions of the placenta for VI and VFI. However, we were unable to demonstrate a decreasing gradient in any of the parameters from basal plate to chonionic plate either in pre-eclampsia or normal pregnancy (Tables I-IIT)

\section{Discussion}

The principal results of this study are: (a) the $3 \mathrm{D}$ parameters of vascularity and flow intensity were lower in pre-eclampsia compared to normal 


\section{Mid Region}

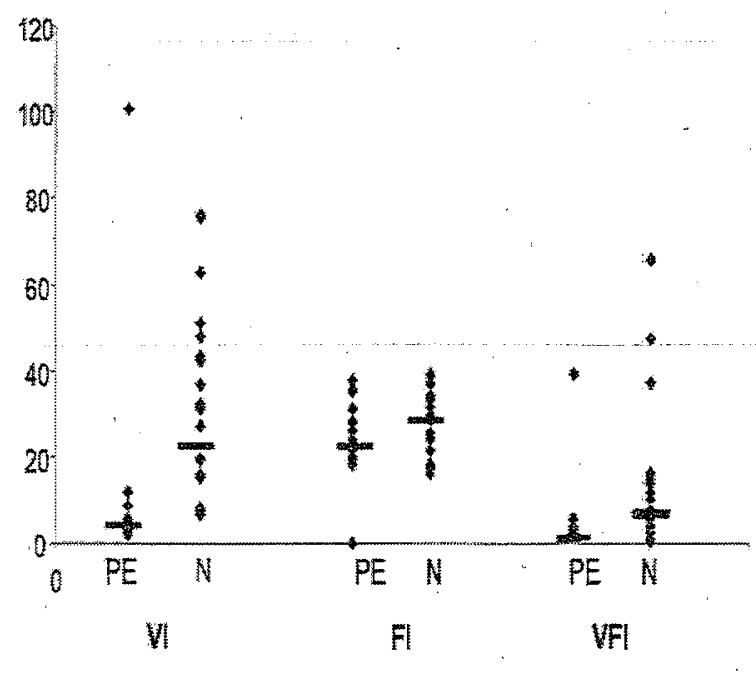

Figure 4. Plot for $V I$, FI and $V F I$ in pre-clampsia (PE) and normal pregnancy $(N)$ at the mid region of the placenta. The horizontal bar indicates the median for VI and VFI and mean for FI.

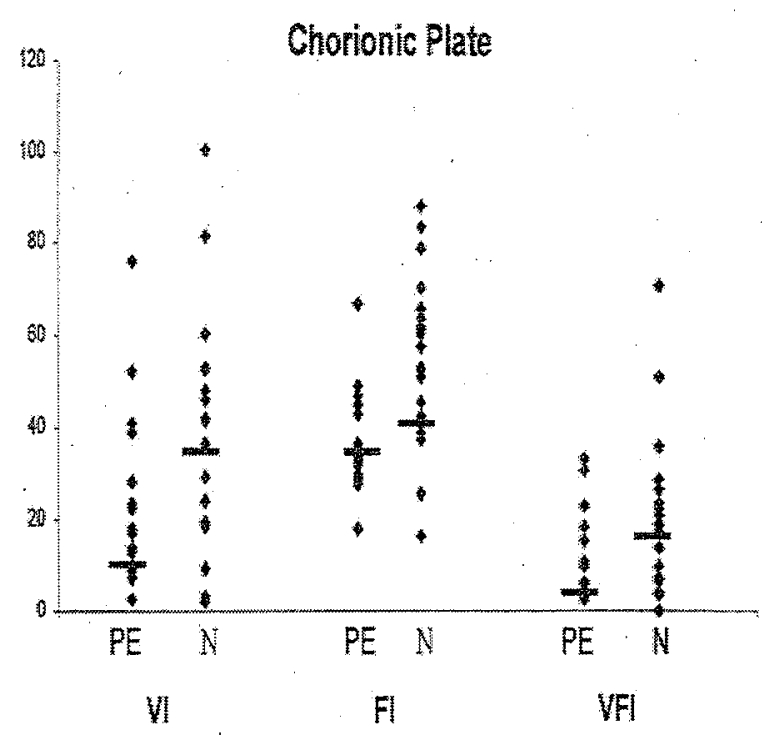

Figure 5. Plot for VI, FI and VFI in pre-clampsia (PE) and normal pregnancy $(N)$ at the chorionic plate. The hotizontal bar indicates the median for VI and VFI and mean for FI.

pregnancy with a statistically significant difference in most of the regions studied. (b) We were not able to demonstrate a decreasing gradient in these parameters from the basal plate towards the chorionic plate, either in pre-eclampsia or normal pregnancy.

The strengths of this study are that confounding variables such as machine settings were controlled for. Gestationa 1 age, BMI and placental'site were also accounted for using linear regression.
As pre-eclampsia and IUGR are a part of the same spectrum of placental disorders, our data would be consistent with that by Guiot et al. [3], where a reduction in $3 \mathrm{D}$ parameters of vascularity and flow intensity was demonstrated in severe IUGR. Our study goes further and demonstrates that in preeclampsia, this reduction is apparent in all regions of the placenta and is statistically different in most regions.

The reasons for the high variability of our data miay be due to a number of factors. Despite the precautions taken, there is still an inherent bias in deciding where to obtain a sample. The effect of sampling at varying depths may also account for the variability. Although we have adjusted for placental site and BMI, we have not adjusted for depth of insonnation per se.

Guiot et al. [3] suggested that of the three indices, FI was the most stable with the least amount of variability. Our results are consistent with this and our values for $\mathrm{FI}$ showed an approximately normal distribution in pre-eclampsia and normal pregnancy in all three regions of placenta.

Previous work [14] using Magnetic resonance imaging (MRD) had demonstrated a significant trend for vascularity to reduce in a systematic fashion from the basal plate to the chorionic plate in normal pregnancy. This observation would be consistent with our current understanding that blood has to travel through relatively narrow (albeit transformed) spiral arteries in order to reach the relatively wide estuary of the intervillous space. However, using $3 \mathrm{D}$ ultrasound we were not able to demonstrate this gradient. The reasons for this are unclear. The basal plate has a large concentration of spiral arteries whilst the chorionic plate has a large concentration of blood vessels of foetal origin. Therefore, the vascularity parameters at both the basal and chorionic plate may actually be similar and cancel out the potential vascularity gradient.

Perhaps the greatest weakness with this study is that the indices FI, VI and VFI do not transiate into the readily understood concept of classical perfusion. Perfusion is measured in millilitres per minute per gram of tissue. Whilst the indices may reflect vascularity and flow intensity [12], they are not measurements of perfusion in the physiological sense. Furthermore, as the attenuation of signal is heavily dependent on depth of insonnation, these parameters may not be suitable for use in obstetric practice. Its use in gynaecology is perhaps less problematic as the probe is usually adjacent to the structures under study [17]. Other workers $[18,19]$ have investigated the concept of fractional moving blood volume (FMBV). FMBV relates more closely to classical perfusion and it is not dependent on depth [17]. Perhaps workers in obstetrics should concentrate their efforts on FMBV instead. 
Declaration of interest: The authors report no conflicts of interest. The authors alone are responsible for the content and writing of the paper.

\section{References}

1. Lume1l NO, Nylund LE, Lewander R, Sarby B. Uteroplacental blood flow in pre-eclampsia measurements with indium-113m and a computer-linked gamma camera. Clin Exp Hypereas B 1982;1:105-117.

2. Roberts JM, Redman CW. Pre-eclampsia: more than pregnancy-induced hypertension. Eancet 1993;341:1447-1451.-.

3. Guiot C, Gaglioti P, Oberto $M$, Piccoli E, Rosato R. Is three dimensional power Doppler ultrasound useful in the assessment of placental perfusion in normal and growth restricted pregnancies? Ultrasound Obstet Gynecol 2008;31 $171-176$.

4. Merce LT, Barco MJ, Bau S. Reproducibility of the sudy of placental vascularization by three-dimensional power Doppler. I Perinat Med 2004;32:228-233.

5. Nowark PM, Nardozza LM, Araujo junior E, Rolo LC Moron AF. Comparison of placental volume in early pregnancy using multiplanar and VOCAL methods. Placenta 2008;29:241-245.

6. $\mathrm{Yu} \mathrm{CH}$, Chang $\mathrm{CH}$, Ko HC, Chen WC, Chang FM. Assessment of placental fractional moving blood volume using quantitative three-dimensional powet Doppler ultrasound Ulrrasound Med Biol 2003;29:19-23.

7. Zalud I, Shaha S. Evaluation of the utero-placental circulation by three-dimensional Doppler ultrasound in the second trimester of normal pregnancy. I Matem Fetal Neonatal Med 2007;20:299-305.

8. Jones NW, Hutchinson ES, Brownbill P, Crocker IP, Eccles D, Bugg GJ, Raine-Fenning NJ. In virro dual perfusion of human placental lobules as a flow phantom to investigate the relationship between fetoplacental flow and quantitative $3 \mathrm{D}$ Doppler angiography. Placenta 2008;29:1-6.

9. Raine-Fenning NJ, Nordin NM, Ramnarine $\mathrm{KV}$, Campbell BK, Clewes JS, Perkins A, Johnson IR. Determining the relationship between three-dimensional power Doppler data and true blood flow characteristics: an in-vitro flow phantom experiment. Ultrasound Obstet Gynecol 2008;32. $540-550$.

10. Schulten-Wijman MJ, Struijk PC, Brezinika C, De Jong, $N$ Steegers. Evaluation of volume vascularization index and flow index: a phantom study. Ultrasound Obstet Gynaecol 2008;32:560-564.

11. Aicazar $J$, Rodriguez $D$, Royo $P$, Gaivan $R$, Ajossa $S$, Guerriero S. Intraobserver and interobserver reproducibility of 3-dimensional power Doppler vascular indices in assessment of solid and cystic-solid adnexal masses. J Ultrasound Med 2008;27:1-6.

12. Raine-Fenning NJ, Campbell BK, Clewes JS, Kendall NR, Johnson IR. The reliability of virtual organ computer-aided analysis (VOCAL) for the semi quantification of ovarian, endomerrial and sub endometrial perfusion. Ultrasound Obstet Gynecol 2003;22:633-639.

13. Pairleiner $H$, Steiner $H$, Hasenoehrl G, Staudach A. Threedimensional power Doppler sonography: imaging and quantifying blood flow and vascularization. Ultrasound Obstet Gynecol 1999;14:139-143.

14. Ong S. Possible structural alterations in pre-eclampsia/TUGR a cause or consequence of reduced placental perfusion [dissertation]. University of Notringham; 2003.

15. Raine-Fenning NJ, Nordin NM, Ramnarine KV, Campbel BK, Clewes IS, Perkins A, Johnson IR. Evaluation of the effect of machine settings on quantitative three-dimensional power Doppler angiography: an in-vitro flow phantom experiment. Ultrasound Obster Gynecol 2008;32:551-559.

16. Bland $J M$, Alman DG. The use of transformations when comparing two means. BMJ 1996;312:1153.

17. Welsh A. Opinion, quantification of power Doppler and the index 'fractional moving blood volume' (FMBV). Ultrasound Obstet Gynecol 2004;23:323-326.

18. Hernandez-Andrade $E$, Jansson $T$, Ley $D$, Bellander $M$, Persson $M$, Lingman $G$, Marsal $K$. Validation of fractional moving blood volume measurement with power Doppler ultrasound in an experimental sheep model. Uitrasound Obstet Gynecol 2004;23:363-368.

19. Hernandez-Andrade $E$, Thuring-Jonsson A, Jansson $T$, Lingman G, Marsal K. Lung fractional moving blood volume in normally grown and growth restricted foetuses. Clin Physiol Funct imaging 2004;24:69-74. 